\title{
BMJ Global Health Impact of community education on heat-related health outcomes and heat literacy among low-income communities in Karachi, Pakistan: a randomised controlled trial
}

Junaid Abdul Razzak, ${ }^{1}$ Priyanka Agrawal (D) ,2 Zaheer Chand, ${ }^{3}$ Saadia Quraishy, ${ }^{4}$ Abdul Ghaffar (1) , ${ }^{5}$ Adnan A Hyder ${ }^{6}$

\section{ABSTRACT}

To cite: Razzak JA, Agrawal P, Chand Z, et al. Impact of community education on heat-related health outcomes and heat literacy among low-income communities in Karachi, Pakistan: a randomised controlled trial. BMJ Global Health 2022;7:e006845. doi:10.1136/ bmjgh-2021-006845

Handling editor Seye Abimbola

Received 8 July 2021 Accepted 3 January 2022

Check for updates

\section{(c) Author(s) (or their} employer(s)) 2022. Re-use permitted under CC BY-NC. No commercial re-use. See rights and permissions. Published by BMJ.

For numbered affiliations see end of article.

\section{Correspondence to} Dr Junaid Abdul Razzak; junaid.razzak@med.cornell.edu
Background Extreme heat exposure is a growing public health concern. In this trial, we tested the impact of a community health worker (CHW) led heat education programme on all-cause mortality, unplanned hospital visits and changes in knowledge and practices in Karachi, Pakistan.

Methods The Heat Emergency Awareness and Treatment trial was a community-based, open-label, two-group, unblinded cluster-randomised controlled trial that implemented a CHW-led educational intervention between March and May 2018 in Karachi, Pakistan. We randomly assigned (1:1) 16 clusters, each with $~ 185$ households or 1000 population, to the intervention or usual care (control group). We collected data on all-cause mortality, unplanned hospital visits, evidence of heat illness through surveillance and a knowledge and practice survey during the summer months of 2017 (preintervention) and 2018 (postintervention).

Findings We recruited 18554 participants from 2991 households (9877 individuals (1593 households) in the control group and 8668 individuals (1398 households) in the intervention group). After controlling for temporal trends, there was a $38 \%$ (adjusted OR $0.62,95 \% \mathrm{Cl} 0.49$ to 0.77 ) reduction in hospital visits for any cause in the intervention group compared with the control group. In addition, there was an improvement in many areas of knowledge and practices, but there was no significant difference in all-cause mortality.

Interpretation A CHW-led community intervention was associated with decreased unscheduled hospital visits, improved heat literacy and practices but did not impact all-cause mortality. CHWs could play an essential role in preparing communities for extreme heat events. Trial registration number NCT03513315.

\section{INTRODUCTION}

Heatwaves are prolonged periods of unusually high temperatures that noticeably affect the health of the elderly, those with comorbidities and the urban poor. ${ }^{12}$ Driven by climate

\section{Key questions}

What is already known?

- Most studies studying the effectiveness of community-based interventions to target heatrelated illnesses are limited to high-income countries that have developed public health management strategies to respond to heatwaves. However, these studies do not show conclusive evidence to highlight the effectiveness of these approaches. There is a lag in planning and response to heat-related illnesses in low-income settings across countries, and the little evidence on population-based estimates was limited to observational studies.

What are the new findings?

- This study designed and tested a heat emergency awareness and treatment (HEAT) intervention, developed using current evidence and relevance to lowresource settings. The HEAT intervention comprises customised health messages coupled with information, education and communication materials to optimise the delivery of those messages, especially for communities with limited access to resources such as water, electricity and air-conditioning. There was a $38 \%$ reduction in the primary outcome of unscheduled hospital visits for any illness in the postintervention phase. In addition, there was an improvement in knowledge of the symptoms, risk factors and emergency interventions required to save the lives of victims with heatstroke. Also, the study showed that an educational intervention through community health workers could impact morbidity in poor, urban communities. Longer-term studies will be needed to confirm our findings.

What do the new findings imply?

- A community-based approach to address the heat mortality and morbidity among the most vulnerable could help communities better prepare for heatwaves and potentially reduce the heat-related burden of death and disability in low-income settings. 
change, extreme heat exposure is a rapidly evolving global public health issue. ${ }^{1}$ During the past 20 years, there has been a $50 \%$ increase in heat-related mortality among adults 65 and older. ${ }^{3}$ In 2018 alone, 296000 people died due to extreme heat exposure globally. ${ }^{1}$ Extreme heat exposure leads to morbidity and mortality through direct temperature dysregulation causing heat exhaustion and heat stroke though most of the health impact is through exacerbation of illnesses such as diabetes and hypertension resulting in a higher incidence of acute illnesses such as myocardial infarction and stroke. ${ }^{4}$ The economic cost of extreme heat on a global level is estimated to be 302 billion work hours lost in $2019 .^{5}$ Evidence from primarily high-income cities show that systematic policy level changes to reduce exposure to extreme heat can improve overall mortality and morbidity. ${ }^{67}$

City dwellers are at a significantly greater risk for extreme heat exposure. Due to the urban heat island effect, cities have a $3.5^{\circ} \mathrm{C}-12^{\circ} \mathrm{C}$ higher temperature than surrounding areas. ${ }^{89}$ Over the years, cities in many highincome countries and a few low-income and middleincome countries (LMICs) have developed 'heat action plans' comprising citywide interventions to reduce heat exposure for those most at risk. ${ }^{71}{ }^{11}$ A recent systematic review on the impact of heat adaptation strategies on heat-related mortality and morbidity reported that $90 \%$ of published research emanated from high-income countries. ${ }^{12}$ These limitations highlight the growing need to develop and test strategies to adapt and protect the most vulnerable in low-income settings from the negative impacts of heat. ${ }^{13} 14$

Within communities, neighbourhoods and individual households have varying levels of vulnerability to extreme heat and require targeted interventions based on household-level risk. ${ }^{15}$ Community-based, householdlevel heat interventions targeting the most vulnerable urban communities have not been tested in LMICs through a controlled trial. Additionally, little data exists on the role of community health workers (CHWs), a critical frontline workforce in many settings in preparing communities for heatwaves.

We hypothesised that in populations with extremely limited resources, a contextually relevant, simple, educational intervention aimed at reducing heat exposure and facilitating early treatment, delivered through CHWs, can result in improved knowledge and practices as well as a decrease in the incidence of all-cause deaths and hospitalisations. We called the educational intervention the Heat Emergency Awareness and Treatment (HEAT) intervention.

\section{METHODS}

\section{Study design and participants}

The HEAT trial was an open-label, prospective, two-armed, unblinded, cluster-randomised, community-based trial conducted in Ibrahim Hyderi, located in Korangi District of the northern part of Karachi, Pakistan. Ibrahim Hyderi is one of the oldest areas of Karachi and is home to many different communities representing various cultural and language groups. These ethnic groups included Sindhis, Katchis, Bengalis, Pakhtuns, Balochis, Muhajirs and Hazara and differed in the language, dietary habits, education level, income level, mobility and predominant occupation.

The Aman Foundation, our local partner, has had a preexisting CHW programme in Ibrahim Hyderi, providing services to improve maternal and child health through screening and treatment of non-communicable diseases to about 100000 people in the area. The Aman CHW programme was supported by a telehealth programme to disseminate health messages and provide a telephonebased 24/7 health helpline. The pre-existing CHW programme had divided the area into 30 neighbourhoods (or 'paras') consisting of relatively homogenous ethnic populations of about 3000 each, served by one CHW, usually a female resident of the same community.

The health services available to the Ibrahim Hyderi community included the Ibrahim Hyderi Sindh Government Hospital (IHSGH) and many private and charity clinics. The IHSGH was primarily used for outpatient clinics and some basic inpatient care. For emergency care, the population generally used either a charity hospital about $5 \mathrm{~km}$ away or a larger government hospital about $13 \mathrm{~km}$ away.

\section{Randomisation and masking}

We followed a two-step sampling strategy. First, we randomly selected sixteen paras from 30 through a random draw. To determine which of the paras were cases and controls, we then stratified the paras by ethnicity, and half of the paras from each ethnic group were assigned to either the intervention or control arms using the second random draw. The second draw was carried out to minimise confounding caused by an unequal distribution of ethnic groups. The randomisation sequence was not concealed or blinded. Data collectors were unaware of the intervention and control distribution during the preintervention phase. All paras and households in Ibrahim Hyderi were eligible to be enrolled in the study.

We selected study households using the existing maps of clusters located in the centre of each cluster, starting approximately in the centre of para and enrolling houses clustered around the centre. If a family refused to participate in the study, we enrolled the adjoining house until we reached a sample size of approximately 1200 persons per cluster. There were no provisions for interim data analysis, and there were no guidelines for early stopping

\section{Sample size}

To calculate the sample size, we assumed that the all-cause death rate of Korangi district was the same as for Pakistan, that is, 7 per 1000 population. ${ }^{16}$ To achieve $80 \%$ power to detect a difference between the group proportions of $20 \%$ in the primary outcome of all-cause death from the baseline at a significance level of 0.05 , a minimum of 
7120 people were required in each group, that is, at least 890 subjects in each of the 16 clusters. To account for lost to follow-up, we planned to enrol 1200 individuals per cluster (approximately 170 households) for a total of 19200 individuals. We excluded all other households from each para once the sample size was reached.

\section{The intervention}

The HEAT intervention comprises customised and contextual health messages for (1) the prevention of and (2) early recognition of heat-related illnesses. We developed the intervention through a multistep, iterative process in collaboration with the Aman Foundation. First, we reviewed the literature on community-based interventions for heat illnesses from India, Pakistan, the USA, the UK, and those published by WHO. ${ }^{4-61117-19} \mathrm{We}$ have published the literature review results elsewhere. ${ }^{20}$ Based on the literature, the Aman Community Health Programme team and investigator jointly drafted health messages which were reviewed by ten public health and emergency care experts, four from the USA, one from India and five from Pakistan. We conducted two meetings with international experts (one in-person) and three meetings with local experts in Pakistan (all in-person) to review and finalise the draft messages. The six members of the International Advisory Group represented expertise in heat emergencies, public health, environmental sciences, and earth and planetary sciences. There were five members of the National Advisory Group consisting of a professor of civil engineering department from a local engineering university, a representative of an environmental health advocacy group, head of the largest emergency department in the city, director of the provincial meteorology department and a journalist interested in environment and health. After the initial review by the International and National Advisory groups, we asked six community health nurses (CHNs) working in Ibrahim Hyderi to review and provide feedback regarding the local applicability and acceptability of the key messages. We conducted three focus group discussions and six in-depth interviews with community members, CHWs, and healthcare providers to further inform our intervention. ${ }^{21}$ The messages were translated into Urdu and Sindhi by the local team from Aman Foundation. The intervention was pilot tested in a non-study community of Ibrahim Hyderi. The feedback was to simplify the messaging further, using concrete examples during the sessions and removing the use of air conditioners and excessive use of bathing as an intervention due to electric and water scarcity in the community.

The final HEAT intervention included key messaging on risk factors, symptoms associated with heat-related illnesses, individual and household level preventative measures, dietary modification, early recognition of heat illness and steps to manage patients with possible heat illness. (See attached brochure in online supplemental material). Some of the key messages used in the communications were (1) wearing lightweight, light-coloured, loosely fitted clothes; (2) carrying a bottle of cold water with you when you are out and about; (3) staying indoors and, if possible, in a well-ventilated place; (4) wearing a hat or if possible or using an umbrella for shade and (5) limiting outdoor activities to morning and evening hours during extreme heat (online supplemental appendices 1 and 2).

The intervention was delivered by a team of ten CHWs, two community health supervisors (CHS), and two CHNs. The team worked full time for the Aman Foundation and did not receive any additional incentive or remuneration besides their regular salary from the Foundation. The investigators trained the CHWs, CHS, and CHNs through a 2-day workshop lasting approximately 12 hours. Topics covered included an introduction to climate change, the global trend of heatwaves, individualbased and community-based risk factors for heat illnesses, the diagnosis and management of heat illnesses at the community and household level. Additionally, sessions were held to demonstrate communication best practices, and mock sessions were held for the household visit and community meetings. The study team evaluated CHWs' understanding of the content and their ability to communicate and answer any questions through a series of mock scenarios. The study leadership held weekly sessions for the implementation team during the intervention period to answer any questions as the intervention was rolled out.

\section{Procedures}

We carried out HEAT intervention in March and April of 2018 and divided it into two main activities, individual household visits and neighbourhood meetings. During the individual household visits, the CHWs used the HEAT pamphlets and posters to discuss the risk factors, symptoms, preventive measures, including dietary modifications, recognition and early management of potential health illnesses. Each session lasted about 20-25 min and was attended by everyone available at home at the time of the visit. CHWs answered any questions, discussed potential barriers and solutions. During the 8 weeks of intervention, each CHW visited each household in the intervention clusters four times for a total of 5420 household visits. On average, each CHW visited 13 household visits per day.

Additionally, CHWs conducted 80 neighbourhood meetings to engage those not traditionally at home. The sessions followed a pattern similar to the household visits but lasted longer and were generally more interactive. A total of 80 such sessions were conducted and were attended by a total of 1628 individuals. We did not track how many people attended more than one such session. At the end of both sessions, community members were given pamphlets printed in Urdu and Sindhi languages summarising the discussion (online supplemental appendices 1 and 2).

\section{Activities in control clusters}

Table 1 summarises activities in both intervention and control clusters. Control clusters had a similar data 
Table 1 Study activities and timelines

\begin{tabular}{|c|c|c|c|}
\hline Study phase & Timelines & Intervention community & Control community \\
\hline Pre-intervention & $\begin{array}{l}\text { May 2017-February } \\
2018\end{array}$ & & \\
\hline Baseline household survey & May 2017 & One visit & One visit \\
\hline Community surveillance & May-July 2017 & Household visit every 2 weeks & Household visit every 2 weeks \\
\hline Baseline KAP & Jan-February 2018 & Household KAP Survey & Household KAP Survey \\
\hline Intervention & March-April 2018 & & \\
\hline Community group sessions & & $\begin{array}{l}\text { Eighty community awareness } \\
\text { sessions with } 1628 \text { people in } \\
\text { attendance. }\end{array}$ & $\begin{array}{l}\text { No Heat intervention. Regular } \mathrm{CHW} \\
\text { visits for maternal and child health }\end{array}$ \\
\hline Household visits & & $\begin{array}{l}5428 \text { household visits with each } \\
\text { house visited four times }\end{array}$ & \\
\hline Post-intervention & May-November 2018 & & \\
\hline Community surveillance & May-July 2018 & Household visit every 2 weeks & Household visit every 2 weeks \\
\hline Household KAP Survey & Sep-October 2018 & KAP survey of all households & KAP survey of all households \\
\hline $\begin{array}{l}\text { Intervention in the control } \\
\text { community }\end{array}$ & November 2018 & No activity & $\begin{array}{l}\text { HEAT intervention in all households } \\
\text { in the control communities by the } \\
\text { same CHWs }\end{array}$ \\
\hline
\end{tabular}

CHW, community health worker; HEAT, Heat Emergency Awareness and Treatment; KAP, knowledge, attitude and practices.

collection strategy (described below) but did not receive the heat intervention. However, after the postintervention data collection was completed, the control clusters received the same intervention.

\section{Data collection}

Table 1 summarises the intervention and control communities' study phases and field activities.

To measure deaths and illnesses requiring hospital visits and monitor symptoms of heat illness, we established a community-based surveillance system during the three warmest months in Karachi (May, June, July in 2017 and 2018). Trained data collectors visited each study household in the intervention and control cluster every other week for a total of five visits per household. The data collectors were from the same community, were employed by Aman Foundation for other health and research-related activities, and were trained in the data collection by the study team. Data was collected through a structured questionnaire, which was peer-reviewed and pretested before final implementation. All data were collected electronically using android tablets. During the first visit, the data collectors obtained detailed demographic and health information on each family member and information about the size of the house, building material, including the material used in the roof, availability of water, electricity, air-conditioning, water cooler, refrigerator and electricity generator. Most homes in Ibrahim Hyderi were built on an 80 sq. yard $(<720$ square feet) plot of land. The size of the home reflected the socioeconomic status and the crowding in the house and was therefore included as an independent variable.

Similarly, in Karachi, houses or apartments facing west or having windows westward, locally called 'west open,' are considered desirable due to the cooling effect of the eastward breeze. We, therefore, included 'west open' as an independent variable. Similarly, houses without windows were also identified and included in the analysis. We asked about the water source but did not ask if the water was potable.

In the subsequent four visits, the data collectors obtained information on any illness, including signs, symptoms, exposure to heat and whether hospital-based care was sought during the past 2 weeks. In case of death, the cause of death was obtained from the head of the household. To assess knowledge, attitude and practices (KAP), we surveyed each household in the control and intervention cluster and interviewed the head of the household. In households where men worked as fishermen and were not present at the time of the survey, the female head of the household was interviewed. This survey was conducted in Jan and February of 2018, before the intervention, and in September and October of 2018, after the postintervention data collection (table 1). The questionnaire for the KAP survey was developed by the research team based on the literature review and feedback from the international and national advisory groups. No prior example of heat KAP survey was available from our literature review. The questionnaire was peer-reviewed by the International and National Advisory Committees and was pretested on 12 individuals from clusters that were not part of the study. Formal validation of the KAP questionnaire was not conducted. The KAP survey was an android-based questionnaire with 117 questions, of which 71 were knowledge questions, 41 were practice questions and 5 were attitude questions (online supplemental appendix 3). 
For community surveillance and KAP data, several data quality checks were included in the e-questionnaire, minimising the chances of entering incorrect or irrelevant data and maximising data integrity. Data underwent two verification levels, and the data management team cleaned the data and ensured its completion. ${ }^{22}$ First, field supervisors checked all the data to ensure their completion and accuracy. Second, the data management team cleaned the data, identified any missing information and ensured that the data on the household matched with the Global Positioning System (GPS) location obtained automatically at the time of data collection.

For May, June and July in 2017 and 2018, the team maintained a log of publicly available average, maximum and minimum temperature provided on the Pakistan Meteorological Department website. ${ }^{23}$

\section{Outcomes}

The study's primary outcomes were a composite of allcause mortality and all-cause emergency hospital visits. Many studies on heat interventions have used all-cause mortality and hospital visits as outcomes. ${ }^{6}{ }^{24-26}$ Since our focus was on severe illnesses requiring visits to the hospital emergency departments, we excluded visits to an outpatient clinic or a primary care physician
The study's secondary outcomes were any change in KAP towards heat-related illnesses within the community. Only those messages that were part of the HEAT intervention were included in the analysis. A more specific measure of heat illness, such as the presence of heat stroke or heat exhaustion, was not included as the outcome measure because of the non-specific nature of symptoms and lack of reasonable certainty in making these diagnoses at a population level based on available information.

\section{Statistical analysis}

All data were analysed using STATA V.15.1 quantitative statistical software. ${ }^{27}$ Descriptive statistical analyses reflected the distribution of socio-demographic characteristics of the sample population on the household level across control and intervention groups in the form of counts and proportions. Mortality rates were calculated for the 3 months of the data collection and annualised by multiplying with a factor of $4 . \chi^{2}$ tests were applied to test the association between pre-and post-intervention outcomes for all-cause mortality, admission to a healthcare facility due to an illness, and presence of any symptoms of heat-related illnesses.

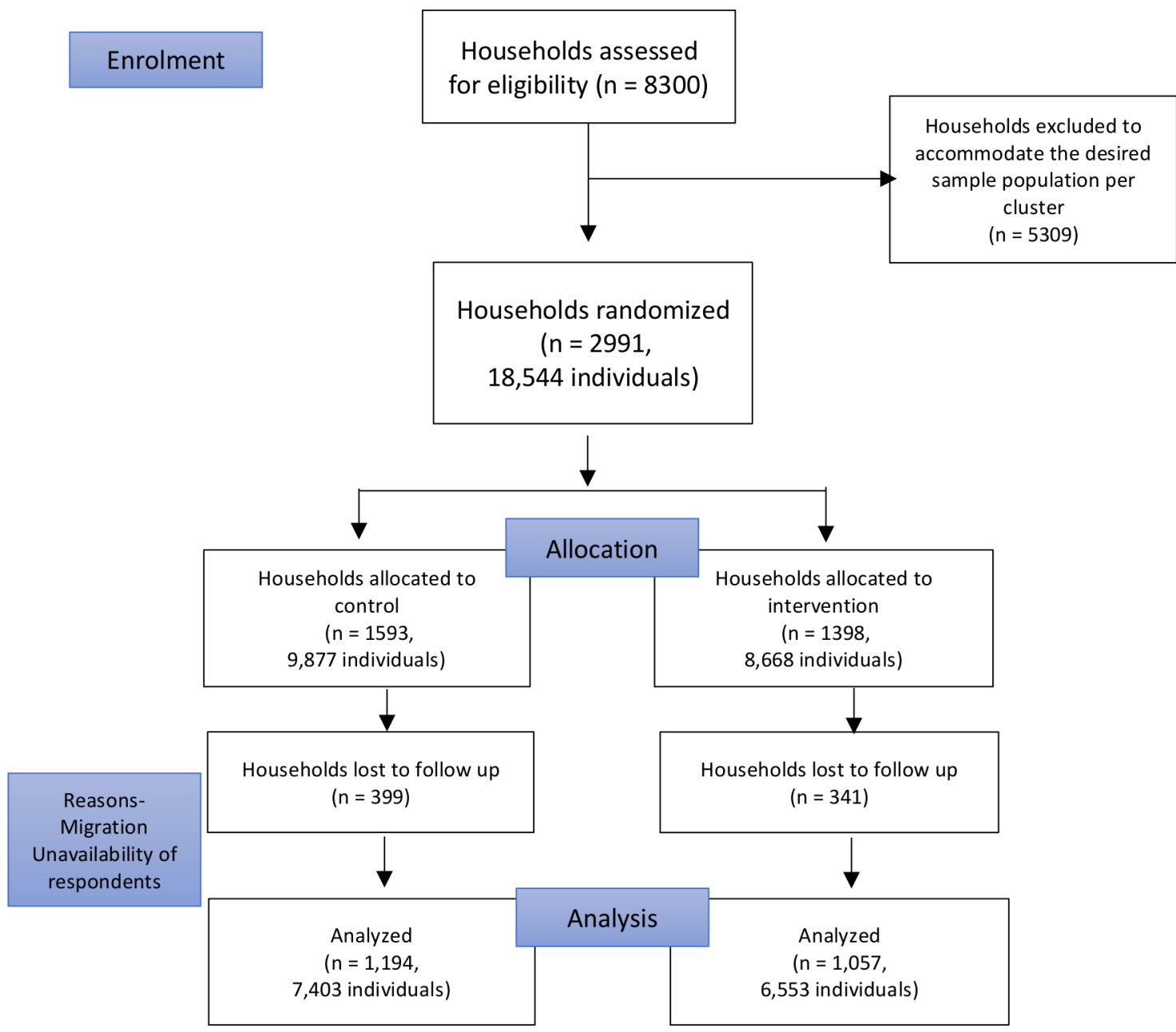

Figure 1 Study design and sample size. 
Table 2 Baseline demographic and housing structure characteristics of the population, March 2017

\begin{tabular}{|c|c|c|c|c|}
\hline Characteristics & Total population & Control & Intervention & $P$ value \\
\hline \multicolumn{5}{|l|}{$\operatorname{Sex}^{*}(n=16203)$} \\
\hline Male & $8538(52.69)$ & $4426(52.79)$ & $4112(52.59)$ & 0.136 \\
\hline Female & $7665(47.31)$ & $3958(47.21)$ & $3707(47.41)$ & \\
\hline \multicolumn{5}{|l|}{$\operatorname{Age}^{*}(n=15792)$} \\
\hline$<5$ & $1814(11.48)$ & $921(11.41)$ & $893(11.57)$ & 0.331 \\
\hline $5-18$ & 4599 (29.12) & $2350(29.11)$ & $2249(29.14)$ & \\
\hline $19-45$ & $7380(46.73)$ & $3751(46.46)$ & $3629(47.01)$ & \\
\hline $46-64$ & $1770(11.21)$ & $918(11.37)$ & $852(11.04)$ & \\
\hline$>65$ & $229(1.45)$ & $133(1.65)$ & $96(1.24)$ & \\
\hline \multicolumn{5}{|c|}{ Education level of the head of the household $+(n=2906)$} \\
\hline No & $2250(77.43)$ & $1174(77.80)$ & $1076(62.12)$ & 0.251 \\
\hline Any & $656(22.57)$ & $335(22.20)$ & $321(37.88)$ & \\
\hline \multicolumn{5}{|l|}{ Family size } \\
\hline Four members or less & $903(33.30)$ & $503(35.05)$ & $400(31.35)$ & 0.045 \\
\hline Five to 6 members & $781(28.80)$ & $418(29.11)$ & $363(28.45)$ & \\
\hline More than six members & $1028(37.91)$ & $515(35.86)$ & $513(40.20)$ & \\
\hline \multicolumn{5}{|c|}{ Household income (US\$, daily)† $(n=2304)$} \\
\hline Less than US\$2 & $1127(48.91)$ & $498(43.38)$ & $628(54.37)$ & $<0.001$ \\
\hline US $\$ 2$ or more & $1177(51.09)$ & $650(56.62)$ & $537(45.63)$ & \\
\hline \multicolumn{5}{|c|}{ House description and size $\nmid(n=2707)$} \\
\hline Hut & $31(1.15)$ & $18(1.25)$ & $13(1.02)$ & 0.327 \\
\hline House (<80 sq. yards) & $1838(67.87)$ & 995 69.29) & $843(66.33)$ & \\
\hline Houses (>80 sq. yards) & $481(17.76)$ & $245(17.06)$ & $236(18.57)$ & \\
\hline Flats/apartments & $357(13.19)$ & $178(12.40)$ & $179(14.08)$ & \\
\hline Any window in the house, yes & $2448(90.17)$ & $1264(51.63)$ & $1184(48.37)$ & $<0.001$ \\
\hline Westward facing house, yes & $1308(48.18)$ & $744(56.88)$ & $564(43.12)$ & $<0.001$ \\
\hline \multicolumn{5}{|l|}{ Roof type $(n=2710) \dagger \ddagger$} \\
\hline Non-concrete & $547(20.18)$ & $359(25.02)$ & $188(14.75)$ & $<0.001$ \\
\hline Concrete & $2163(79.82)$ & $1076(74.98)$ & 1087 (85.25) & \\
\hline \multicolumn{5}{|l|}{ Water source $(n=2699) \dagger \S$} \\
\hline Outside home & $1240(45.94)$ & $626(43.84)$ & $614(48.31)$ & 0.020 \\
\hline Inside home & $1459(54.06)$ & $802(56.16)$ & $657(51.69)$ & \\
\hline \multicolumn{5}{|l|}{ Other resources $\dagger$} \\
\hline Electricity, yes & $2416(88.99)$ & $1279(52.94)$ & $1137(47.06)$ & 0.938 \\
\hline Telephone, yes & $30(1.10)$ & $18(60.00)$ & $12(40.00)$ & 0.438 \\
\hline Cellphone, yes & $2139(78.78)$ & $1127(52.69)$ & $1012(47.31)$ & 0.578 \\
\hline Generator, yes & $137(5.05)$ & $69(50.36)$ & $68(49.64)$ & 0.531 \\
\hline Room coolerףl, yes & $15(0.52)$ & $6(40.00)$ & $9(60.00)$ & 0.313 \\
\hline Television, yes & $1947(71.71)$ & $1059(54.39)$ & $888(45.61)$ & 0.018 \\
\hline
\end{tabular}

*Number of individuals.

†Number of households.

$\ddagger$ Non-concrete includes thatch/bamboo/wood/mud/cardboard/plastic/iron sheets/asbestos; concrete includes T-iron/wood/brick/reinforced brick cement/Reinforced cement concrete (RCC)/tile beam.

§Inside home-tap, hand pump, well, boring: outside home-community tap, community hand pump, tanker, others.

ICColers that work on the evaporative cooling where evaporated water is used to cool the air. 
Table 3 Health outcomes across the preintervention and postintervention periods

\begin{tabular}{|c|c|c|c|c|c|}
\hline \multirow[b]{2}{*}{ Variables } & \multicolumn{2}{|l|}{ Control, (\%) } & \multicolumn{2}{|l|}{ Intervention, (\%) } & \multirow{2}{*}{$\begin{array}{l}\text { Adjusted OR } \\
(95 \% \mathrm{Cl})^{\star}\end{array}$} \\
\hline & Preintervention & Postintervention & Preintervention & Postintervention & \\
\hline $\begin{array}{l}\text { Deaths from any } \\
\text { cause (rate per } 1000 \\
\text { per year) }\end{array}$ & $17(2.29)$ & $16(2.47)$ & $21(2.93)$ & $17(2.80)$ & 0.86 (0.34 to 2.19$)$ \\
\hline $\begin{array}{l}\text { Unscheduled } \\
\text { hospital visit (rate per } \\
1000 \text { per year) }\end{array}$ & $231(124.7)$ & 377 (233.0) & $311(173.6)$ & $311(204.8)$ & $0.62(0.49$ to 0.77$)$ \\
\hline
\end{tabular}

*Adjusted odds of the outcome in the intervention group compared with the control group in the postintervention group.

The data on knowledge, preventive measures and actions during an emergency based on the key messages from the intervention were retrieved from the more extensive KAP data. Change in the proportion of household representatives who responded 'yes' to a variable between the control and intervention groups preintervention and postintervention was calculated to represent secondary outcomes. Adjusted OR (aOR), accounting for the change in positive responses in the postintervention period for the intervention group compared with the change in responses in the preintervention group for the control group, were calculated to measure differences in primary and secondary outcomes between the intervention and the control groups.

We developed a logistic regression model to test for association between the rates of an unscheduled hospital visit and several household indicators such as the size of family, size education of the head of household, water source, electricity and television and building material used in the house and the roof. ${ }^{28}$ An interaction term for the group (control/intervention) and time (preintervention/postintervention) was also included in the regression to test whether the change seen across each outcome variable was actually due to the intervention.

Written consent was obtained from the heads of each household for the households to be included in the study. We used verbal consent where participants were unable to read and write. The consent process occurred at the household level, and the Aman foundation's research team was responsible for the consent process. The consent process occurred before the community surveillance began within the community.

\section{Public involvement}

We organised community meetings to discuss the project before launching it. CHWs were from the Ibrahim Hyderi community and were involved in the design of the intervention and the study's conduct as data collectors. Community members were not directly involved in the study design, recruitment or conduct of the study. We conducted multiple session with the community members in Karachi to inform them of the results. A HEAT policy document was developed as part of the study and disseminated to the city government and a dissemination seminar was also organised in the federal capital of Islamabad. There was no burden of intervention on the study participants or larger community.

\section{RESULTS}

We enrolled 18544 individuals from 2991 households from the sixteen clusters (figure 1). Of these, 1593 households (9877 people) were from the control clusters, and 1398 (8668 people) were from the intervention clusters. Just over half $(52.69 \%)$ of the population were males, $87 \%$ were below 45 years, while only $1.5 \%$ of the population was over the age of 65 years (table 2 ). More than three-fourth $(76.13 \%)$ of the population had no education, and the distribution was similar for heads of households $(77.4 \%)$. About half of the households had an income of less than US $\$ 2$ per day (US dollar to Pakistani Rupees currency exchange rate of June 2018). Twenty per ent of households had a non-concrete roof type, and about half had potable water inside their homes $(54 \%)$. Electric power was available to $89 \%$ of the households. Overall, the intervention and control populations were similar except for the proportion with an income level of $<\mathrm{US} \$ 2$ per day (56.6 vs $45.3, \mathrm{p}<0.00$ ) and the percentage of homes with a non-concrete roof $(65.5 \%$ and $34.4 \%, \mathrm{p}<0.00)$. Less than $1 \%$ of households refused to participate in the study.

\section{Health outcomes}

Complete follow-up data were available for 2251 (75.25\% of the initial sample) households, of which 1194 were from the control group ( $74.5 \%$ of the initial sample) and 1057 (75.6\% of the initial sample) from the intervention group. In the preintervention phase, the annualised rate of all-cause mortality in the intervention group was 11.72 deaths per 1000 population (2.92 per 1000 population over the 3 months), while in the control group, it was 9.18 per 1000 population (2.29 per 1000 population over the 3 months). In the postintervention phase, the annualised all-cause mortality rate in the intervention group decreased to 11.2 per 1000 population (2.80 per 1000 over the 3 months), while in the control group, it increased to 9.88 per 1000 population (2.47 per 1000 population over 3 months). The adjusted odds of death in the intervention group decreased following the intervention (OR 
Table 4 Results of health outcomes following communitybased educational intervention

\begin{tabular}{ll}
\hline Characteristics & Hospital visits/deaths \\
\hline Group & \\
Control & Reference \\
Intervention & $1.20(0.92-1.57)$ \\
Time &
\end{tabular}

\begin{tabular}{ll}
\hline Preintervention & Reference \\
\hline Postintervention & $0.99(0.81-1.22)$ \\
\hline Family size & \\
\hline Size of family (four or less) & Reference \\
\hline 4-6 members & $1.20(0.89-1.60)$ \\
\hline More than six members & $1.31(1.02-1.71)^{*}$ \\
\hline House type & \\
\hline House (<80 sq. yards) & Reference \\
\hline Hut & $1.22(0.49-3.06)$ \\
\hline House (>80 sq. yards) & $1.32(1.01-1.73)^{*}$ \\
\hline Flats & $1.28(0.93-1.75)$ \\
\hline Education of head of household & \\
\hline No & Reference \\
\hline
\end{tabular}

Any education $\quad 1.19(0.93-1.52)$

$\begin{array}{ll}\text { Roof type } & \\ \text { Non-concrete } & \text { Reference } \\ \text { Concrete } & 1.24(0.93-1.65)\end{array}$

Ventilation

\begin{tabular}{ll} 
No & Reference \\
Yes & $0.90(0.63-1.29)$ \\
\hline Open towards west & \\
\hline No & Reference \\
Yes & $1.05(0.85-1.31)$ \\
\hline Water source & \\
\hline Inside home & Reference \\
\hline Outside home & $1.11(0.89-1.38)$ \\
\hline Electricity & \\
\hline No & Reference \\
Yes & $1.01(0.72-1.42)$ \\
\hline Television & \\
\hline No & Reference \\
\hline Yes & $0.84(0.66-1.06)$ \\
\hline
\end{tabular}

${ }^{*} \mathrm{P}<0.05$.

†Non-concrete include thatch/bamboo/wood/mud, cardboard, plastic, iron sheets, asbestos, t-iron, wood, brick; concrete include reinforced brick cement/Reinforced cement concrete, tile beam.

$0.8695 \%$ CI 0.34 to 2.19 ) though the reduction was not statistically significant.

For an illness requiring an unscheduled visit to a hospital, we found an overall increase in the frequency of hospital visits during the post-intervention phase $(\mathrm{n}=542,3.72 \%$ vs $\mathrm{n}=688,5.48 \%$; $\mathrm{p}<0.001)$ in both control and intervention groups. The AOR for hospital visits in the intervention group was 0.62 (95\% CI 0.49 to 0.77$)$ (table 3).

The logistic regression model results for the association between the unscheduled visit to a hospital and various demographic and household variables showed that except for a family size of more than six members, there was no statistically significant difference between the groups (table 4). There was no association between the education level, house size, type of roof, water availability, electricity and ownership of a television, and risk of an unscheduled hospital visit.

\section{Knowledge and practice outcomes}

In our preinterventionand postintervention KAP survey, we found an improvement in the knowledge and practices in both control and intervention groups. However, for the most critical messages delivered during the intervention, we found greater improvement in knowledge and practices among the intervention group than the control. For example, households in the intervention arm in the post-intervention phase were 2.37 times more likely to be aware of high temperature as a symptom of heat illness than those in the control group in the preintervention phase. Similarly, there was higher recognition of symptoms such as weakness (OR: 1.72) and tachycardia (OR: 1.31) as symptoms of heat illness. Taking a shower to reduce body temperature (OR: 0.68 ); changing lifestyle such as avoiding going outside in the afternoon (OR: 2.78) ) and modifying time to cook (1.94) were also more acceptable in the postintervention phase in the intervention group (table 5).

\section{DISCUSSION}

We found that a CHW-led, community-based educational intervention was associated with no reduction in mortality and a $38 \%$ relative reduction in unscheduled hospital visits in the intervention group compared with the control group when adjusted for the differences at baseline. We also found an improvement in the community's ability to recall many of the signs and symptoms of heat exhaustion and heatstroke, identify risk and preventive strategies, and recall steps to ensure life-saving emergency care. However, these results have to be considered in the context that, despite the randomisation, intervention and control populations had different baseline rates of mortality and hospital visits, and in the postintervention period, there was an overall increase in hospital visits not explained by temperature differences between the two time periods.

Our study population likely represents some of the most climate-vulnerable population groups worldwide and highlights the challenges of developing and implementing potential extreme heat interventions in populations with limited infrastructure. The most frequently recommended heat mitigating interventions require water and electric power. However, these utilities were 
Table 5 Change in knowledge, attitude and practice outcomes for heat illness preintervention and postintervention between control and intervention groups

\begin{tabular}{|c|c|c|c|c|c|}
\hline \multirow[b]{2}{*}{ Variables } & \multicolumn{2}{|l|}{ Control n (\%) } & \multicolumn{2}{|l|}{ Intervention n (\%) } & \multirow[b]{2}{*}{$\begin{array}{l}\text { Adjusted OR } \\
(95 \% \mathrm{Cl})\end{array}$} \\
\hline & $\begin{array}{l}\text { Preintervention } \\
(\mathrm{n}, \%)\end{array}$ & $\begin{array}{l}\text { Postintervention } \\
\text { (n, \%) }\end{array}$ & $\begin{array}{l}\text { Preintervention } \\
(\mathrm{n}, \%)\end{array}$ & $\begin{array}{l}\text { Postintervention } \\
\text { (n, \%) }\end{array}$ & \\
\hline Age $>65$ is a risk factor & $1172(90.6)$ & $1119(84)$ & $851(83.4)$ & $1068(89)$ & 0.88 (0.79 to 1.04$)$ \\
\hline High temperature is a symptom & $361(27.9)$ & $622(46.7)$ & $345(33.9)$ & $674(56.2)$ & $2.37(2.10 \text { to } 2.67)^{\star}$ \\
\hline Increased weakness is a symptom & $503(38.9)$ & $585(43.9)$ & $273(26.9)$ & $608(50.7)$ & $1.72(1.53 \text { to } 1.93)^{\star}$ \\
\hline Worsening mental status is a symptom & $125(9.7)$ & $183(13.7)$ & $175(17.2)$ & $246(20.5)$ & $1.88(1.62 \text { to } 2.21)^{\star}$ \\
\hline Increased heart rate is a sign & $210(16.3)$ & $292(22)$ & $92(9.1)$ & $266(22.2)$ & $1.31(1.12 \text { to } 1.55)^{*}$ \\
\hline Working outside is a risk factor & $256(19.8)$ & $144(10.8)$ & $260(25.6)$ & $152(12.7)$ & $0.47(0.40 \text { to } 0.55)^{\star}$ \\
\hline $\begin{array}{l}\text { Avoid going outside between } 11: 00 \text { - } \\
\text { 15:00 hours }\end{array}$ & $80(6.2)$ & $199(14.9)$ & $87(8.8)$ & $256(21.3)$ & $2.78(2.29 \text { to } 3.37)^{\star}$ \\
\hline Reduce time in kitchen during afternoon & $1051(81.3)$ & $931(69.8)$ & $745(73.4)$ & $808(67.3)$ & $1.94(1.59 \text { to } 2.38)^{\star}$ \\
\hline Victim should be moved to a cooler area & $254(19.6)$ & $189(14.2)$ & $234(23.1)$ & $230(19.2)$ & $0.73(0.63 \text { to } 0.85)^{\star}$ \\
\hline Heavy clothing should be removed & $175(13.5)$ & $146(11)$ & $142(14)$ & $148(12.3)$ & $0.82(0.68 \text { to } 0.96)^{*}$ \\
\hline Helpline should be called & $54(4.2)$ & $47(0.1)$ & $67(6.6)$ & $41(3.4)$ & $0.66(0.49 \text { to } 0.88)^{*}$ \\
\hline Wet sponging should be considered & $160(12.3)$ & $126(9.4)$ & $159(15.7)$ & $118(9.8)$ & $0.65(0.54 \text { to } 0.78)^{\star}$ \\
\hline Shower should be considered & $1012(78.3)$ & $857(64.3)$ & $738(72.7)$ & $863(72)$ & $0.68(0.61 \text { to } 0.78)^{*}$ \\
\hline
\end{tabular}

${ }^{*} \mathrm{P}<0.05$

not consistently available in many households in our study site. The concept of vulnerability to extreme heat needs to evolve with an improved understanding of the epidemiology of heat illnesses and their physiological, social, and environmental determinants. ${ }^{24} 29$ We believe traditional measures of heat exposure and risks, such as temperature, humidity, and age, may overlook other, more complex household-level social and economic risks such as the affordability and availability of water and electricity, number of people per household, the design of the housing unit and access to emergency healthcare. ${ }^{15} 3031$ Similarly, age $>65$ is the focus of most interventions that may not have the same impact in our study population, where only $1.5 \%$ of the total population was in that age group.

There is growing evidence supporting government-run, regional interventions for reducing the health impact of extreme heat. ${ }^{203233}$ Analysis of the heat action plans from multiple European cities showed a significant decrease in deaths during heatwaves and improved communities' KAP. ${ }^{34-36}$ Further, targeted interventions focusing on high-risk groups such as the elderly and those with known chronic medical conditions through door-to-door checks, focused health messaging and close follow-up with primary physicians have also shown a significant reduction in mortality rates. ${ }^{37} 38$ In Ahmedabad, India, the citywide implementation of a heat warning system coupled with a widespread communication effort led to a decrease in the number of heat-related deaths reported to the hospital. ${ }^{39}$ A quasi-experimental study from Chongqing, China, tested a broader set of interventions, including a heat-specific healthcare network, early warning system and preparation, a 24-hour health helpline and doctors' training on heat illnesses. The study found a significant improvement in the incidence of heat-related illnesses in the subset of rural populations measured through two surveys 1 year apart. ${ }^{40}$ In another community-based study set in Jinan City, China, the elderly in two urban and two rural settings were randomised to receive governmentsanctioned subsidies during high-temperature periods to keep workers home and flexible scheduling versus no intervention. ${ }^{41}$ The study found improved KAP scores in the intervention group.

Our study, however, focused on enhancing the community's response through existing community resources, independent of government-sanctioned reliefs and interventions. Thus, we attempted to replicate circumstances that exist in many similar LMIC cities where local governments, often strapped for resources, have limited ability to enforce heat intervention plans. Yet, we believe that a government-run, heat-health action plan would likely have a much more significant impact, be more cost-effective and sustainable, and potentially, have synergistic effects when combined with community-based household-level interventions.

Our findings have several implications for future preparedness for extreme heat exposures. We demonstrated that CHWs could provide necessary community education leading to a potential change in behaviour and health outcomes. CHWs are recognised as critical to many health systems, especially those in LMICs, and are beginning to be recognised as agents of change for planetary health. ${ }^{42}$ The study served as a proxy to suggest that with some additional training in heat prevention, CHWs can create behaviour change within communities to reduce heat exposure and blunt the effects of extreme heat while other system-wide, resource-intensive interventions are implemented. ${ }^{32}$ 
Our study has several limitations. First, like most heat intervention studies, we focused on all-cause morbidity and mortality as the primary outcome instead of specific heat-related mortality and morbidity. This was due to the difficulty in diagnosing heat illnesses in communities, especially where febrile infectious illnesses are common. ${ }^{43-45}$ Second, our study did not collect information on the prevalence of non-communicable diseases such as diabetes or hypertension for the population. We only collected that information once someone the in community reported the symptoms of heat illness. Third, across assumed equal distribution of individual level exposure to heat, and we did not measure changes in the exposure between the 2 years. Personal heat exposure data collection has been conducted in athletes and military personnel but less in civilian settings. ${ }^{546}$ We believe, measuring individual-level exposure to heat stress would help standardise the exposure and is possible with the available technology. ${ }^{47}$ Fourth, while encouraging, our results are based on only two-point estimates and do not prove with certainty the cause-and-effect relationship. Further, our intervention lasted only 1 year, making it difficult to study the effects of confounders between the 2 years. For example, average maximum temperatures during preintervention months were slightly higher than post-intervention, while minimum temperatures were the same (35.2 and 28.2 in the preintervention phase vs 36.0 and 28.2 ' $\mathrm{C}$ in the postintervention phase). ${ }^{48} \mathrm{Simi}-$ larly, in the postintervention period, the city of Karachi had a significant epidemic of chikungunya infection. It is not clear how this affected our study area. ${ }^{43}$ Finally, it is also important to recognise that the KAP questionnaire was designed specifically for the local context and needs validation in other settings.

\section{CONCLUSION}

Our study identified a potentially promising role for CHWs in improving the resilience of highly vulnerable low-income urban communities against extreme heat. If proven through longer-term studies in multiple settings, the HEAT intervention developed through this study could lead to significant public health benefits for the most vulnerable populations globally.

\section{Author affiliations \\ ${ }^{1}$ Department of Emergency Medicine, Weill Cornell Medicine, New York, New York, USA \\ ${ }^{2}$ International Health, Johns Hopkins University Bloomberg School of Public Health, Baltimore, Maryland, USA \\ ${ }^{3}$ MLE Department, Aman Foundation, Karachi, Pakistan \\ ${ }^{4}$ MLE Department, Aman Foundation/West London Heath Trust, London, UK \\ ${ }^{5}$ Alliance for Health Policy and Systems Research, World Health Organization, Geneve, Switzerland \\ ${ }^{6}$ MLE Department, George Washington University Milken Institute of Public Health, Washington, District of Columbia, USA}

Twitter Junaid Abdul Razzak @JunaidRazzakMD

Contributors JAR led the conceptualisation of study design and implementation of the project as well as the data analytics and manuscript writing. PA assisted in the data management and analysis as well as developed multiple drafts of the manuscript. ZC and SQ were local partners who assisted in the implementation of the study on the ground, were involved in data collection and management and provided technical assistance in the development of the manuscript. AG and AAH provided technical support and feedback in multiple drafts of the manuscript. JAR is responsible for the overall content as guarantor and accepts full responsibility for the finished work and the conduct of the study, had access to the data, and controlled the decision to publish.

Funding This research project was funded by Elrha's Research for Health in Humanitarian Crises (R2HC) Programme, Save the Children Fund ('SCUK'), which aims to improve health outcomes by strengthening the evidence base for public health interventions in humanitarian crises. $\mathrm{R} 2 \mathrm{HC}$ is supported by the UK Foreign, Commonwealth and Development Office (FCDO), the Wellcome Trust and the UK National Institute for Health Research (NIHR).

\section{Competing interests None declared.}

Patient consent for publication Consent obtained directly from patient(s)

Ethics approval This study was approved by Institutional Review Boards of Johns Hopkins University, USA (IRB00089663), and the Aga Khan University, Pakistan.

Provenance and peer review Not commissioned; externally peer reviewed.

Data availability statement No data are available. Not applicable.

Supplemental material This content has been supplied by the author(s). It has not been vetted by BMJ Publishing Group Limited (BMJ) and may not have been peer-reviewed. Any opinions or recommendations discussed are solely those of the author(s) and are not endorsed by BMJ. BMJ disclaims all liability and responsibility arising from any reliance placed on the content. Where the content includes any translated material, BMJ does not warrant the accuracy and reliability of the translations (including but not limited to local regulations, clinical guidelines, terminology, drug names and drug dosages), and is not responsible for any error and/or omissions arising from translation and adaptation or otherwise.

Open access This is an open access article distributed in accordance with the Creative Commons Attribution Non Commercial (CC BY-NC 4.0) license, which permits others to distribute, remix, adapt, build upon this work non-commercially, and license their derivative works on different terms, provided the original work is properly cited, appropriate credit is given, any changes made indicated, and the use is non-commercial. See: http://creativecommons.org/licenses/by-nc/4.0/.

\section{ORCID iDs}

Priyanka Agrawal http://orcid.org/0000-0003-1314-7143

Abdul Ghaffar http://orcid.org/0000-0002-8629-4526

\section{REFERENCES}

1 Watts N, Amann M, Arnell N, et al. The 2020 report of the Lancet countdown on health and climate change: responding to converging crises. The Lancet 2021;397:129-70.

2 Campbell S, Remenyi TA, White CJ, et al. Heatwave and health impact research: a global review. Health Place 2018;53:210-8.

3 Hales S, Kovats S, Lloyd S, et al. Qualitative risk assessment of effects of climate change on selected causes of death, 2030s and 2050s. Geneva, Switzerland: World Health Organization, 2014.

4 Bobb JF, Obermeyer Z, Wang Y, et al. Cause-Specific risk of hospital admission related to extreme heat in older adults. JAMA 2014;312:2659-67.

5 Kjellstrom T, Freyberg C, Lemke B, et al. Estimating population heat exposure and impacts on working people in conjunction with climate change. Int J Biometeorol 2018;62:291-306.

6 Koppe C, Kovats S, Jendritzky G. Heat-waves: risks and responses. World Health Organization. Regional Ofice for EuropeCopenhagen, Denmark, 2004.

7 McGregor GR, Bessemoulin P, Ebi K. Heatwaves and health: guidance on warning-system development. Geneva, Switzerland: World Meterological Organization and World Health Organization, 2015.

8 Waite M, Cohen E, Torbey H, et al. Global trends in urban electricity demands for cooling and heating. Energy 2017;127:786-802.

9 Salamanca F, Georgescu M, Mahalov A, et al. Anthropogenic heating of the urban environment due to air conditioning. J Geophys Res 2014:119:5949-65

10 Lowe D, Ebi KL, Forsberg B. Heatwave early warning systems and adaptation advice to reduce human health consequences of heatwaves. Int J Environ Res Public Health 2011;8:4623-48. 
11 Knowlton K, Kulkarni S, Azhar G, et al. Development and Implementation of South Asia's First Heat-Health Action Plan in Ahmedabad (Gujarat, India). Int J Environ Res Public Health 2014;11:3473-92.

12 Boeckmann M, Rohn I. Is planned adaptation to heat reducing heat-related mortality and illness? A systematic review. BMC Public Health 2014:14:1-13.

13 Horton RM, Mankin JS, Lesk C, et al. A review of recent advances in research on extreme heat events. Current Climate Change Reports 2016;2:242-59.

14 Stocker TF, Qin D, Plattner GK. Climate change 2013. The physical science basis. Working group I contribution to the fifth assessment report of the Intergovernmental panel on climate Change-Abstract for decision-makers; Changements climatiques 2013. les elements scientifiques. contribution Du Groupe de travail I Au cinquieme rapport d'evaluation Du Groupe d'experts intergouvernemental sur I'evolution Du CLIMAT-Resume a l'intention des decideurs. New York, USA: Cambridge University Press, 2013.

15 Nayak SG, Shrestha S, Kinney PL, et al. Development of a heat vulnerability index for new York state. Public Health 2018;161:127-37.

16 Pakistan key indicators. Key country indicators. World Health Organization, 2020.

17 Extreme heat. Natural disasters and severe weather. Available: https://www.cdc.gov/disasters/extremeheat/index.html [Accessed 8 Nov 2021].

18 Heat and health. Available: https://www.who.int/news-room/factsheets/detail/climate-change-heat-and-health [Accessed 8 Nov 2021]

19 Public Health England. Heatwave plan for England, in Public Health, England. NHS England.

20 Hasan F, Marsia S, Patel K, et al. Effective community-based interventions for the prevention and management of heat-related illnesses: a scoping review. Int J Environ Res Public Health 2021;18:8362.

21 Khan UR, Ahmed N, Naeem R, et al. Heat emergencies: perceptions and practices of community members and emergency department healthcare providers in Karachi, Pakistan: a qualitative study. Int $J$ Environ Res Public Health 2021;18:4736.

22 Sidi F, Hassany P, Panah S. Data quality: A survey of data quality dimensions. in 2012 International Conference on Information Retrieval \& Knowledge Management, 2012: 300-4.

23 Pakistan Meteorological Department, Government of Pakistan. Available: https://www.pmd.gov.pk/en/ [Accessed 8 Nov 2021]

24 World Health Organization. Improving Public Health Responses to Extreme Weather/Heat-Waves. WHO Regional Office for Europe, Copenhagen, Denmark, 2009.

25 Sheffield PE, Herrera MT, Kinnee EJ, et al. Not so little differences: variation in hot weather risk to young children in New York City. Public Health 2018;161:119-26.

26 Shindell D, Zhang Y, Scott M, et al. The effects of heat exposure on human mortality throughout the United States. GeoHealth 2020;4:e2019GH000234.

27 StataCorp L. Stata data analysis and statistical software. Special Edition Release 2007;10:733.

28 Vittinghoff E, Glidden DV, Shiboski SC. Regression methods in biostatistics: linear, logistic, survival, and repeated measures models. Springer Science \& Business Media, 2006.

29 Gronlund CJ. Racial and socioeconomic disparities in heat-related health effects and their mechanisms: a review. Current Epidemiology Reports 2014;1:165-73.

30 Tran K, Azhar G, Nair R, et al. A cross-sectional, randomized cluster sample survey of household vulnerability to extreme heat among slum dwellers in Ahmedabad, India. Int J Environ Res Public Health 2013:10:2515-43.

$31 \mathrm{Li} \mathrm{J,} \mathrm{Xu} \mathrm{X,} \mathrm{Wang} \mathrm{J.} \mathrm{Analysis} \mathrm{of} \mathrm{a} \mathrm{community-based} \mathrm{intervention} \mathrm{to}$ reduce heat-related illness during heat waves in Licheng, China: a quasi-experimental study. Biomedical and environmental sciences 2016;29:802-13.

32 Hess JJ, Lm S, Knowlton K, et al. Building resilience to climate change: pilot evaluation of the impact of India's first heat action plan on all-cause mortality. J Environ Public Health 2018;2018:1-8.

33 Matthies F, Bickler G, Marin NC. Heat-health action plans: guidance. Copenhagen, Denmark: World Health Organization Regional Office for Europe, 2008.

34 Fouillet A, Rey G, Wagner V, et al. Has the impact of heat waves on mortality changed in France since the European heat wave of summer 2003? A study of the 2006 heat wave. Int J Epidemiol 2008;37:309-17.

35 Morabito M, Profili F, Crisci A, et al. Heat-Related mortality in the Florentine area (Italy) before and after the exceptional 2003 heat wave in Europe: an improved public health response? Int $\mathrm{J}$ Biometeorol 2012;56:801-10.

36 de' Donato F, Leone M, Scortichini M, et al. Changes in the effect of heat on mortality in the last 20 years in nine European cities. results from the phase project. Int J Environ Res Public Health 2015;12:15567-83.

37 Liotta G, Inzerilli M, Palombi L, et al. Social interventions to prevent heat-related mortality in the older adult in Rome, Italy: a quasiexperimental study. Int J Environ Res Public Health 2018;15:715.

38 Nitschke M, Krackowizer A, Hansen A, et al. Heat health messages: a randomized controlled trial of a preventative messages tool in the older population of South Australia. Int J Environ Res Public Health 2017;14:992.

39 Nastar M. Message sent, now what? A critical analysis of the heat action plan in Ahmedabad, India. Urban Science 2020;4:53.

40 McGregor GR, Vanos JK. Heat: a primer for public health researchers. Public Health 2018;161:138-46.

$41 \mathrm{Xu} \mathrm{X,} \mathrm{Li} \mathrm{J,} \mathrm{Gao} \mathrm{J,} \mathrm{et} \mathrm{al.} \mathrm{Effective} \mathrm{analysis} \mathrm{of} \mathrm{a} \mathrm{community-based}$ intervention during heat waves to improve knowledge, attitude and practice in a population in Licheng district, Jinan City, China. $J$ Public Health 2018;40:573-81.

42 Behera M, Behera D, Satpathy S. Planetary health and the role of community health workers. Journal of Family Medicine and Primary Care 2020;9:3183.

43 Rehman K. Potential Chikungunya epidemics in Pakistan: Act before it's too late. Journal of Ayub Medical College Abbottabad 2019;31:474-5.

44 EPA U. Excessive heat events guidebook. Washington: EPA 430-B06-005. US Environmental Protection Agency, 2006.

45 Yamamoto T, Fujita M, Oda Y. Evaluation of a novel classification of heat-related illnesses: a multicentre observational study (heat stroke study 2012). International journal of environmental research and public health 20181962;15.

46 Hass AL, Ellis KN. Using wearable sensors to assess how a heatwave affects individual heat exposure, perceptions, and adaption methods. Int J Biometeorol 2019;63:1585-95.

47 Kuras ER, Hondula DM, Brown-Saracino J. Heterogeneity in individually experienced temperatures (IETs) within an urban neighborhood: insights from a new approach to measuring heat exposure. Int J Biometeorol 2015;59:1363-72.

48 Synoptic/ Metars Data/ seismic report. Available: https://rmcpunjab. pmd.gov.pk/metData.php [Accessed 8 Nov 2021]. 